\title{
Mathematical Modelling and Ideology in the Economics Academy: competing explanations of the failings of the modern discipline?
}

\author{
Tony Lawson \\ Faculty of Economics, University of Cambridge, UK \\ Tony.Lawson@econ.cam.ac.uk
}

\begin{abstract}
The widespread and long-lived failings of academic economics are due to an over-reliance on largely inappropriate mathematical methods of analysis. This is an assessment I have long maintained. Many heterodox economists, however, appear to hold instead that the central problem is a form of political-economic ideology. Specifically, it is widely contended in heterodox circles that the discipline goes astray just because so many economists are committed to a portrayal of the market economy as a smoothly or efficiently functioning system or some such, a portrayal that, whether sincerely held or otherwise, is inconsistent with the workings of social reality. Here I critically examine the contention that a form of political-economic ideology of this sort is the primary problem and assess its explanatory power. I conclude that the contention does not fare very well. I do not, though, deny that ideology of some sort has a major impact on the output of the modern economics academy. However it is of a different nature to the form typically discussed, and works in somewhat indirect and complex ways. Having raised the question of the impact of ideology I take the opportunity to explore its play in the economics academy more generally.
\end{abstract}

\section{Introduction}

One positive consequence of the ongoing economic crisis is that the intellectual malaise of the modern academic discipline of economics is becoming ever more widely recognised. Economics is a discipline that is marked by significant explanatory failure stemming from wildly unrealistic formulations, and has been for many years now (see Lawson 2003, chapter 1).

The reference to specifically academic economics here is not incidental; I want to stress that throughout the discussion my concern is not economics in all its forms or manifestations but economics as it is pursued within the modern academy, which after all is the site from which most strands of the subject emanate.

Elsewhere I have put forward an explanation of the noted academic malaise that draws significantly on ontological theorising, i.e., on theorising the nature of (social) reality. Because my focus here is with examining the power of, and support for, an alternative explanation I do not want to rehearse my own position at length. But in brief, the explanation I elsewhere maintain is that the fundamental problem of modern economics is that methods are repeatedly applied in conditions for which they are not appropriate (see Lawson, 1997; 2003). Specifically, modern academic economics is dominated by a mainstream tradition whose defining characteristic is an insistence that certain methods of mathematical modelling be more or less always employed in the analysis of economic phenomena, and are so in conditions for which they are not suitable.

Fundamental to my argument is an assessment that the application of mathematics involves more than merely the introduction of a formal language. Of relevance here is recognition that mathematical methods and techniques are essentially tools. And as with any other tools (pencils, 
hammers, drills, scissors), so the sorts of mathematical methods which economists wield (functional relations, forms of calculus, etc.) are useful under some sets of conditions and not others.

The specific conditions required for the sorts of mathematical methods that economists continually wield to be generally applicable, I have shown, are a ubiquity of (deterministic or stochastic) closed systems. A closed system is simply one in which an event regularity occurs. Notice that these closures are as much presupposed or required by the 'newer' approaches to mathematical economics, those often referred to as non-linear modelling, complexity modelling, agent-based modelling, model simulations, and so on (including those developed under the head of behavioural or neuro- economics), as they are by the more traditional forms of micro, macro and econometric modelling.

The most obvious scenario in which a prevalence of such closures would be expected is a world 1) populated by sets of atomistic individuals or entities (an atom here being an entity that exercises its own separate, independent, and invariable effect, whatever the context); where 2) the atoms of interest exist in relative isolation (so allowing the effects of the atoms of interest to be deducible/predictable by barring the effects of potentially interfering factors). Not surprisingly the latter two (ontological) presuppositions are easily shown to be implicit in almost all contemporary economic modelling contributions (see Lawson, 2003, chapter 1).

However, explicit, systemic and sustained (ontological) analysis of the nature of social reality reveals the social domain not to be everywhere composed of closed systems of sets of isolated atoms. Rather social reality is found to be an open, structured realm of emergent phenomena that, amongst other things, are processual (being constantly reproduced and transformed through the human practices on which they depend), highly internally related (meaning constituted though [and not merely linked by] their relations with each other - e.g., employer/employee or teacher/ student relations), value-laden and meaningful, amongst much else (see Lawson, 2003 chapter 2).

Clearly if social phenomena are highly internally related they do not each exist in isolation. And if they are processual in nature, being continually transformed through practice, they are not atomistic. So the emphasis on the sorts of mathematical modelling methods that economists employ necessarily entails the construction of economic narratives - including the sorts of axioms and assumptions made and hypotheses entertained - that, at best, are always but highly distorted accounts of the complex phenomena of the real open social system (for lengthy elaborations of all this see e.g., Lawson, 1997; 2003; Edward Fulbrook, 2009). It is thus not at all surprising that mainstream contributions are found continually to be so unrealistic and explanatorily limited.

Employing the term deductivism to denote the thesis that closed systems are essential to social scientific explanation (whether the event regularities, correlations, uniformities, laws, etc., are either a prior constructions or a posterior observations), I conclude that the fundamental source of the discipline's numerous, widespread and long lived problems and failings is precisely the emphasis placed upon forms of mathematical deductivist reasoning ${ }^{1}$.

So much for my own assessment. Many heterodox economists clearly demur, and most of these seemingly hold to the view that a superior explanation of the state of modern economics is provided by focusing on the prevalence of a form of political-economic ideology. The real source of all the failings of the mainstream academic project, according to advocates of this view, is that ideology about how the economic system works gets in the way of explanatorily successful or realistic analysis.

Ideology is a term I have rarely employed, as various heterodox critics have pointed out ${ }^{2}$. Here I address the claim that ideology provides a better, or even an alternative, explanation of the modern

\footnotetext{
${ }^{1}$ This critique of detuctivism of course is not a denial that deductive reasoning can be appropriately employed alongside numerous other forms of logic, reasoning and analysis. In what follows I may occasionally refer not to deductivism but just to mathematical modelling or some such. For a discussion of deductivism as a form of scientific explanation see especially Lawson, 1997, chapter 2; 2003 , chapter 1.

2 Brian O'Boyle and Terrence McDonough (2011) for example suggest that a "lack of an ideological-critique is perhaps the most glaring lacunae for the Lawsonian project, in light of its own philosophical project of critiquing mainstream economics". They add that "the Lawsonian project is unable (or unwilling) to entertain the possibility of an ideological function for mainstream economics"
} 
academic economics' malaise to the one I have advanced and have briefly sketched above. In so doing I take the opportunity to explore the role of ideology in the practices and output of the modern economics academy more generally.

\section{Ideology}

The term ideology was seemingly coined by Count Destutt de Tracy in the late 18th century to define a "science of ideas". Few interpret the category in this way today, however. Almost universally, the current understanding is that the term ideology refers not to the study, but rather to the content, of certain sets of ideas, along with their consequences.

Thereafter, however, interpretations diverge, with very many alternatives to be found in the contemporary literature ${ }^{3}$. Even so, with a little systematising I think most interpretations can be seen either to presuppose, or to reduce to special cases of, two broad systemic conceptions. These are:

1) Ideology $y_{1}$ : a relatively unchallenged set of (possibly distorted or misleading) background ideas that every society or community possesses which forms the basis of, or significantly informs, general opinion or 'common sense', a basis that remains somewhat invisible to most of its members, appearing as 'neutral', resting on preconceptions that are largely unexamined. A consequence is that viewpoints significantly out of line with these background beliefs are intuitively seen as radical, nonsensical or extreme no matter what may be the actual content of their vision.

2) Ideology 2 : a set of ideas designed, or anyway intentionally employed, in order to justify, preserve or reinforce some existing state of affairs, where this state of affairs is preferred, perhaps because it facilitates or legitimates various advantages for some dominant or privileged group, and where these ideas mostly work in the manner described by way of intentionally masking or misrepresenting the nature of reality.

Whether or not these two conceptions are sufficiently comprehensive with regard to the literature on ideology in general, as far I can discern they do cover the interpretations found in the economics literature (and are clearly apparent in the contributions of those who emphasise my apparent neglect of the role of ideology in modern economics). They also cover the viewpoints of many that never mention the term ideology. I should note, though, that those who adopt such a position, including those who explicitly emphasise ideology frequently refer to (what I am calling) modern mainstream economics as neoclassical. The latter is again a term I rarely use, though I take it for the purposes of the current paper that both expressions are intended to refer to the same project, even if there is disagreement as to its nature.

and, worse, that "to follow Lawson in his particular critique of the mainstream is to relinquish the very tools that are needed to uncover 'the anatomy and ideological function of orthodoxy' or indeed its contribution to neoliberal ideology". Other such critics include for example Kanth, 1999, and Guerrien, 2004 (see below).

3 Terry Eagleton (1991, p.2), for example, lists the following interpretations found in the recent literature: a process of production of meanings, signs and value in social life; a body of ideas characteristic of a particular social group or class; ideas which help to legitimate a dominant political power; false ideas which help to legitimate a dominant political power; systematically distorted communication; that which offers a position for a subject; forms of thought motivated by social interests; identity thinking; socially necessary illusion; the conjuncture of discourse and power; the medium in which conscious social actors make sense of their world; action-oriented sets of beliefs; the confusion of linguistic and phenomenal reality; semiotic closure; the indispensable medium in which individuals live out their relation to a social structure; the process whereby said life is converted to a natural reality. 


\section{The ideology theorists}

According to those in effect employing the first conception of ideology, economic theory is found wanting just because, or where, its proponents act upon, but fail seriously to reflect upon, or to challenge, or to treat as other than a given, a set of background intuitions/ideas of efficiently functioning markets or some such. It is the latter intuitions/ideas that constitute the content of the ideology in question. Mainstream theories, it is held, are grounded in such intuitions; and it is just because they are inadequate to real world processes but so unquestioningly and almost unthinkingly maintained, that economics goes so wrong.

According to those instead employing the second interpretation, mainstream economists are viewed as the agents (rather than subjects) of ideology, advancing it with the purpose of sustaining the underlying economic system - so that the proposed explanation of the form of the mainstream lack of explanatory insight and so forth is just this desire to perpetuate the economic status quo using theories that are knowingly inappropriate to it.

These two contentions, though connected, are clearly not identical. In the first case, mainstream economists are viewed as the hapless dupes of the prevailing ideology. In the second case, these same economists knowingly and indeed conspiratorially provide, maintain and promote the ideology. Let me briefly give examples of each interpretation.

Ideology

A version of the former mainstream-as-manifestation-of-background-ideology interpretation is advanced for example by Bernard Guerrien (2004). Criticising my own contributions in particular, Guerrien writes:

"I am only going to consider Lawson's main criticism of neoclassical economics: its "lack of realism". I think that it is not the appropriate objection: all theories lack realism, as they take into consideration only some aspects of reality. Everyone agrees on this, even neoclassical economists. The real problem with neoclassical theory is not its' "lack of realism" but the "ideology" (a word Lawson never uses) that it smuggles in and carries with it"

Having suggested that the real problem is not a lack of realism or (a better term) realisticness, Guerrien proceeds by agreeing that a lack of realisticness nevertheless is a problem, albeit, he supposes, mostly one that lies in the mainstream formulation of structure rather than its accounts of human agency. Guerrien understandably finds the formulations that abound to be somewhat absurd; in fact he goes as far as to talk of 'irrelevant' and 'stupid' models. His main concern, though, is not with the lack of realisticness per se but with the extreme nature of it; with why anyone - and specifically intelligent academics - would choose to reproduce and study constructions that can only be regarded as 'stupid':

"The question is [...]: how such intelligent people can propose - and endlessly study such stupid models?"

Guerrien answers his own question as follows:

"I only see one reason for that: ideology (intuitive beliefs which render them blind)"

This is Guerrien's only elaboration of his understanding of the term. But it does suggest that Guerrien means something like a certain set of beliefs held by the community that are so intuitive in their appeal that their holders do rarely reflect upon them and are mostly blinded to the possibility that the beliefs in question might be wrong or even open to valid criticism ${ }^{4}$.

\footnotetext{
${ }^{4}$ Of course, when or where most people in a community think alike about certain matters, and even 'forget' that there are alternatives to the current state of affairs, we also arrive at Antonio Gramsci's concept of Hegemony.
} 
What is this set of intuitive beliefs that Guerrien has in mind? Following his brief outline of what he means by ideology Guerrien writes:

"Here, the belief alluded to is that "market mechanisms" [...] produce "efficient" results if you abstract from "frictions", "failures", etc. (ignoring these "imperfections" being, for neoclassical theorists, the principal reason of "lack of realism"). As there is a strong link between competitive equilibrium (that is, with auctioneer, etc.) and efficient states - link given by the two Welfare Theorems - then competitive equilibrium must be identified with "perfect market" (as both are supposed to be efficient). In some books (especially those on growth, in the "macro" mood - as those of Romer and Barro and Sala-IMartin), perfect competition and an "omniscient" "representative agent" (or planner) choice are presented as giving the same results. How can a normal person make any sense of this?"

And Guerrien's answer to the question posed in the last sentence, in effect, is that we make sense of this by seeing mainstream economists as essentially cultural or economic dupes, unable to rise sufficiently above or beyond the prevailing ideology of their times.

Ideology $_{2}$

A rather more conspiratorial view of mainstream theory, as itself a form of ideology, is perhaps more common. The self-consciously heterodox Real World Economics Review (formerly the Post-Autistics Review) and its associated Real World Economics Review Blog are replete with contributions where the term ideology is used in this way. An illustrative example is provided by Peter Söderbaum (2009), who describes ideology explicitly as theory serving as a 'means' to achieve a political end:

“'Ideology' stands for a 'means-ends philosophy' and is not limited to more or less established political ideologies like socialism, social democracy, social liberalism or neoliberalism. In this sense, neoclassical economics clearly qualifies as an ideology and as such is more specific and precise than the political ideologies mentioned.

Neoclassical economics tells us about the relevant actors in the economy (consumers, firms and government); about how to understand markets (supply and demand of commodities and of factors of production); about decision-making (optimization) and efficiency (usually a monetary concept or at best cost-efficiency). This way of understanding economics is clearly not neutral but specific in ideological terms" (p. 9)

Elsewhere a colourful statement of the more conspiratorial interpretation of economics as ideology is provided by Rajani Kanth (1999). Kanth, indeed, is quite explicit in the view that (mainstream) "economics is the ruling ideology of the capitalist system" (p. 191). Writing of (mainstream or 'neoclassical') economics as "this crown jewel of capitalist ideology" (p. 191); of "the inherent charlatanism of economic ideology" ( $p$. 189), and so forth, Kanth elaborates as follows:

"To state the moral: the entire enterprise of neo-classical economics is rigged to show that laissez-faire produces optimal outcomes, but for the disruptive operation of the odd externality (a belated correction) here and there (Kanth, 1999, pp. 191-2, emphasis in the original)".

How is this rigging achieved? One component of the strategy is everywhere to stipulate that human beings are rational (meaning optimising) atomistic individuals. A second is the construction of theoretical set-ups or models specified to ensure that (typically unique) optimal outcomes are attainable. 
There are indeed very many economists who do adopt the individualist framework and assumption that individual behaviour is optimal (in the sense of always deriving from optimising decisions in conditions where optimal outcomes are to be had). Perhaps most do. But this is not yet enough to show that the overall economic system is itself optimal in any way. If the claim is that mainstream economists seek to defend the economic system per se, something more is required to guarantee the result that the system is in a sense 'optimal'. This, it is supposed, is achieved by the commonplace construction of an equilibrium framework; the latter being so specified that the actions of isolated optimising individuals somehow (tend to) work to bring an equilibrium position about. Thus Kanth, for example, refers to the "economic science of capitalism" as

"simply irrelevant for being a fantasy world of an ideal rational, capitalism where all motions are mutually equilibriating, in a Newtonian co-ordination of the elements" (Kanth, 1999, p. 194)

In sum, two competing interpretations of the nature of ideology and how it connects to the mainstream tradition of modern economics can be found. The first supposes that mainstream economics is the more or less unrecognised product of ideology, the second sees mainstream economics as itself the ideology perhaps intentionally promoting deception.

If the two interpretations are radically different in their orientation, they do have something significant in common. They both characterise the mainstream project as primarily concerned with producing theories that express capitalism as an efficiently functioning, or otherwise desirable or optimal, system. Thus, according to both sets of accounts the lack of realisticness and so forth of mainstream economics arises just through that project's portrayal of the economy as an efficiently functioning or otherwise desirable system, a portrayal that is regarded as being inconsistent with the way the real world really is.

In this manner the two groups ultimately provide somewhat similar explanations of the enduring failings of the modern mainstream, even if their accounts of the intentions of economists and manner in which ideology impacts are quite different.

\section{An assessment of the political-economic ideology explanations}

My own view is that neither of these explanations of the state of modern economics is sustainable. Remember the phenomenon before us is the generalised explanatory failure and lack of realisticness of formulations across the totality of the mainstream (macro, micro and econometric) output over a large number of years (again see e.g. Lawson, 2003, chapter 1 ).

It is one thing to suggest that mainstream economists mostly suppose that capitalism, as a market centred system, is somehow natural or normal or the best that can be achieved; but it is quite another thing to suppose that much of the output of these economists is even mainly concerned with such issues of political economy. It is a further step still to suppose that mainstream economists in their modelling endeavours everywhere either take it as a matter of unquestioning belief, or are motivated to demonstrate, that the social world in which we live is not merely defensible, but characterised by equilibrium or efficient markets or perfect competition, and so forth. In truth, the social system that is capitalism is, qua social system, barely ever even considered.

Moreover in those cases where economists do focus on questions of market or competitive equilibrium etc., the formulators of the models in question are often careful to stress that their theorising has little connection with the real world anyway and should not be used to draw conclusions about the latter, whether in terms of efficiency or for policy or whatever. Thus, Frank Hahn, a major contributor in this field, writes: 
"[...] it cannot be denied that there is something scandalous in the spectacle of so many people refining the analyses of economic [equilibrium] states which they give no reason to suppose will ever, or have ever, come about. It probably is also dangerous. Equilibrium economics [...] is easily convertible into an apologia for existing economic arrangements and it is frequently so converted" (1970, pp. 88-9).

Elsewhere, Hahn reveals in rather dramatic fashion what he feels should happen if people contemplate using such models for policy:

"When policy conclusions are drawn from such models, it is time to reach for one's gun"

(Hahn, 1982, p. 29).

In truth in those cases where mainstream assumptions and categories are couched in terms of economic systems as a whole they are mainly designed to achieve consistency at the level of modelling rather than coherence with the world in which we live.

This concern for a notion of consistency in modelling practice is true for example of the recently fashionable rational expectations hypothesis, originally formulated by John Muth (1961), and widely employed by those that do focus on system level outcomes. The hypothesis proposes that predictions attributed to agents (being theorised about) are treated as being essentially the same as (consistent with) those generated by the economic model within which the same agents are theorised ${ }^{5}$. As such the proposal is clearly no more than a technique for (consistency in) modelling, albeit a bizarre one. Significantly any assertion that the expectations held (and so model in which they are imposed) are essentially correct, is a step that is additional to assuming rational expectations.

It is a form of modelling consistency (albeit a different one) that underpins the notion of equilibrium itself. In modern mainstream economics the category equilibrium has nothing to do with the features of the real economy (say with the balance of supply and demand -- see e.g., Lawson, 2005; 2006). Economic models often comprise not single, but sets of, equations, each of which is notoriously found to have little relation to what happens in the real world. One question that nevertheless keeps economists occupied with such unrealistic models is whether the equations formulated are mutually consistent in the sense that there 'exists' a vector of values of some variable, say one labelled 'prices', that is consistent with each and all the equations. Such a model 'solution' is precisely the meaning of equilibrium in this context. As such the notion is not at all a claim about the world but merely a (possible) property that a set of equations may or may not be found to possess. The mainstream economists Huw Dixon gets it right when he summarises matters as follows: "At its most general, we can say that 'equilibrium' is a method of solving economic models. At a superficial level, an equilibrium is simply a solution to a set of equations" (Dixon, 1990, p. 356). In short, when mainstream economists question whether an equilibrium 'exists' they merely enquire as to whether a set of equations has a solution.

More to the point, however, the substantive content of mainstream theorising is far wider and more dynamic than a fixed focus on market mechanisms or on conceptions of competitive equilibrium and claims that the market mechanisms lead to efficiency, and such like.

In fact, most mainstream economists, as I say, have never concerned themselves much with the workings of the economic system as a whole (whether via an equilibrium framework or otherwise). The dominant concern, rather, has been, and remains, with highly specific or partial analyses of some highly restricted sectors or forms of behaviour. Very often the focus is on 'micro' decision making or 'behaviour'. Even (or perhaps especially) here though the contributions have more or less always been unrealistic and have rarely if ever generated (as opposed to imported) insight.

\footnotetext{
${ }^{5}$ As Muth himself puts it: "expectations, since they are informed predictions of future events, are essentially the same as the predictions of the relevant economic theory [....] The hypothesis can be rephrased a little more precisely as follows: that expectations of firms (or, more generally, the subjective probability distribution of outcomes) tend to be distributed, for the same information set, about the prediction of the theory (or the "objective" probability distributions of outcomes)" (Muth, 1961, p. 316)
} 
To the extent that it has ever been meaningful for the various disparate results or theorems of these economists to be considered as a whole, the clearest conclusion that can be drawn is that they are mostly wildly inconsistent with each other. So long as the assumptions are tractable mainstream theorists are free to posit anything they want no matter how unrealistic. Competing hypotheses abound, even by the same contributors in different contributions.

If we focus on empirical contributions, specifically, it is clear that there are few attempts to repeat the results of others, progress the results of others, or even acknowledge the results of others. Even econometricians using identical, or almost identical, data sets are regularly found to produce quite contrasting conclusions, usually with little attempt at explanation. The systematic result here, as the econometrician Edward Leamer (1983) observes, is that: "hardly anyone takes anyone else's data analysis seriously" (p. 37).

Furthermore, far from being a conspiracy or a uniformly misled project, mainstream economics lacks agreement even as to the project's purpose or direction. As one of its leading practitioners Ariel Rubinstein acknowledged more than a decade ago:

"The issue of interpreting economic theory is [...] the most serious problem now facing economic theorists. The feeling among many of us can be summarized as follows. Economic theory should deal with the real world. It is not a branch of abstract mathematics even though it utilises mathematical tools. Since it is about the real world, people expect the theory to prove useful in achieving practical goals. But economic theory has not delivered the goods. Predictions from economic theory are not nearly as accurate as those by the natural sciences, and the link between economic theory and practical problems [...] is tenuous at best. Economic theory lacks a consensus as to its purpose and interpretation. Again and again, we find ourselves asking the question 'where does it lead?' " (Rubinstein, 1995, p. 12).

In short, the modern mainstream is not a project whose emphases and explanatory failures are mainly direct manifestations either of intentions to maintain attachment to the existing economic system, or of a blindness to its real nature. At the level of substantive theory, there is far more heterogeneity within mainstream theorising than Guerrien, Kanth and others allow, with relatively little attention focussed on the economic system as a whole, let alone given over to the theorising of its optimality. Indeed at the level of substantive theory the project is marked by overall incoherence and lack of cohesion amongst its various strands, and with significant uncertainty even as to what is worth pursuing.

In fact some recent close critical observers of the economic content of mainstream theories not only do not characterise the mainstream as ideological at the substantive level, but actually portray the mainstream project at this level as pluralist (see for example David Colander et al., 2004 or John Davis 2005). In truth I think this a polite way of saying that the projects flits from fad to fashion in the hope of achieving explanatory successes somewhere. But that aside, at least these authors recognise the obvious heterogeneity and change that characterises the project ${ }^{6}$.

The one (and as far as I can see only) feature that has persistently and comprehensively marked all mainstream contributions, and continues to dominate, is the insistence that methods of mathematical modelling always be employed. And, significantly, this emphasis is by itself sufficient to explain the mainstream deficiencies at all levels including that of economic content. Specifically, and unlike explanations that seek to make ideology at the level of economic content the central factor, explanations in terms of the misplaced emphasis on mathematical modelling can account for mainstream inadequacies

\footnotetext{
${ }^{6}$ Thus, in contradistinction to Guerrien and others, Colander et al. (2004) call attention to what they see as the "changing face of mainstream economics" and criticise heterodox economists for failing to notice such ongoing developments. Specifically, these authors criticise heterodox contributors for adopting an overly "static view of the profession" (p. 486); for referring to the current mainstream as neoclassical; and for missing the "diversity that exists within the profession, and the many new ideas that are being tried out" (p. 487). In fact, Colander et al. insist that "Mainstream economics is a complex system of evolving ideas" (p. 489), and refer to the "multiple dimensionalities that we see in the mainstream profession" (p. 489).
} 
whether couched in terms of explanatory failure, unrealistic formulations, or the project's lack of direction; whether the economic focus is the system as a whole or very partial 'micro' situations; whether the modellers are or are not supporters of the status quo; whether or not data are employed; whatever the substance of the latest fad and fashion to preoccupy, and so on. In consequence, I see little reason in all of this to reject yet the assessment that the misplaced emphasis on mathematical deductivist reasoning provides the better explanation of the rather unhappy state of modern economics.

\section{An alternative conception of ideology in the economics academy}

I have considered the two conceptions of ideology that are most often associated with modern academic economists and I have argued that, in the political-economy garb in which these ideologies are usually presented by opponents of the mainstream, they do not serve easily to account for the explanatory failings of the discipline.

However in so concluding I must stress that it by no means follows that I suppose either that ideology is entirely absent from the modern economics academy, and specifically mainstream economics, or that questions of ideology have no bearing on the latter project's lack of explanatory power. Indeed I am of the definite view that ideology is rife and with significant consequences for mainstream explanatory performance. There are various issues to consider though.

First and foremost, I want briefly to indicate an alternative ideology, a version of ideology ${ }_{1}$ ( a set of background views manifest unquestioningly as if normal or neutral) that I believe does pervade the economics academy, one that is extremely widespread and indeed plays a significant contributory role in the failings of the discipline. But this is a set of beliefs that bears not directly upon the nature of the underlying economic system at all. Rather it is precisely the doctrine that all serious economics must take the form of mathematical modelling.

This ideology, as I am suggesting it to be, usually involves a presumption of an event-regularityseeking (and so prediction-oriented) conception of science along with the complementary belief that mathematics is closely aligned with, and indeed essential to, such a science.

I must stress that the contention I am advancing here is not an arbitrary add-on adopted just because the focus of discussion is ideology. If I am right that the problems of modern economics stem first and foremost from the misplaced attachment to mathematical reasoning despite the record of failure so far, there must be a reason for this emphasis. That reason, I want to suggest, is, in large part at least, the unquestioning, uncritical, taken on trust as normal, blinkered orientation to employing mathematical techniques characteristic of most of those who pursue it. It is blindness to, or an unreasoned dismissive resistance to any suggestion of, any alternative to the idea that wielding mathematical techniques is both essential to science and compulsory if economics is to make a proper contribution. Such a stance amounts precisely to a system of beliefs that is itself a form of ideology (ideology $y_{1}$ ).

Let me emphasise that I am quite aware that there are forms of mathematical systems, methods and techniques beyond those currently and/or traditionally prosecuted by economists. Deductivist forms, presupposing closures of the sort defined above, just happen to be those that economists (so far) find easiest to wield or otherwise most convenient. I do not argue that all forms of mathematical method (including those yet to be invented) must necessarily be inappropriate to social analysis - though I strongly doubt that any will ever prove of general use for addressing/illuminating the sort of capitalist social system in which we currently live. But this is not the issue. My point, rather, is that far from even contemplating, let alone exploring, alternative non-mathematical approaches - where various available alternatives are easily shown to be relevant to, and fruitful for, illuminating the real social system (for illustrations see for example Lawson, 2009a; 2003, chapter 4; 1997, chapter 18) - modern mainstream economists continually seek out mathematical techniques of some kind. It is, to repeat, this unwillingness or apparent inability seriously to contemplate the idea that a serious, fruitful and explanatorily successful 
(science) of economics might be developed that does not rely upon the application of mathematical methods and techniques of some form that indicates the dominant form of the actually prevalent ideology.

\section{Ideology in action}

It can be easily seen that the unquestioned emphasis on mathematical modelling is indeed a form of ideological blindness if a brief examination is made of cases where, for whatever reason, mainstream economists, whether in the form of a few critical contributors, or as a collective body, have come to critically address the explanatory failings of their project. For it is evident that the one feature that is almost never addressed in such endeavour is precisely the emphasis on the employment of mathematical techniques. Even in the very few cases that mainstream contributors recognise or acknowledge that criticisms of the mathematical-modelling emphasis have been made from outside their project, the latter criticisms tend to be summarily dismissed either without serious consideration, or at most with some vague referencing of alternative more appropriate mathematical techniques yet to be developed.

Let me first briefly consider examples of the latter, cases where the issue of the mathematical emphasis itself is at least broached in published mainstream commentaries. Amongst the very few examples I can find are by the 'theorists' Alan Kirman and Frank Hahn, surely amongst the most openminded and reflexive of mainstream economists. However, even in such cases any notion that the mathematical emphasis might be the problem is quickly dismissed rather than seriously entertained.

Kirman, for example, in critically examining the nature and poor performance of mainstream theorising focuses on the individualist emphasis of the enterprise. But in suggesting alternative ways for the mainstream to proceed it is clear that he regards methods of mathematical modelling per se as effectively indispensable. Thus, he writes:

"The argument that the root of the problem [...] [is] that we are confined by a mathematical strait jacket which allows us no escape, does not seem very persuasive. That the mathematical frameworks that we have used made the task of changing or at least modifying our paradigm hard, is undeniable but it is difficult to believe that had a clear well-formulated new approach been suggested then we would not have adopted the appropriate mathematical tools" (Kirman, 1989, p. 137).

I noted above that Frank Hahn does not hesitate to acknowledge that equilibrium theory tells us little about economic reality; and he is especially ill-disposed towards those that would seek to use mainstream models to draw policy conclusions or as a guide to practical action. But the idea that mathematics might be dispensable to economic thinking, or anyway overly emphasised, or commanding too high a proportion of the resources available for economic research, is not afforded serious reflection. To the contrary, he dismisses any suggestion that the modern emphasis on mathematical modelling may be misplaced as "a view surely not worth discussing" (Hahn, 1985, p. 18). And in a major speech to the Royal Economic Society he even counsels that we "avoid discussions of 'mathematics in economics' like the plague" (Hahn, 1992a; see also Hahn, 1992b).

If mainstream economists tend to be blind to, or to ignore, or at best to dismiss, external critiques of the mathematical emphasis how do they react in situations where they at least acknowledge explanatory failure? The ongoing economic crisis provides perhaps a unique insight to this. Recently, possibly the largest numbers of mainstream self-critics ever have been driven to reassess their own practices as a result the ongoing economic crisis and widespread suspicion of, and concern for, if not outright condemnation of, academic economic output. Notably even amongst mainstream economists there have been increased calls for change and numerous claims advanced that changes have indeed been, or are being, made. The situation thus affords an unusual opportunity to assess which parts of academic economic 
practice are most readily regarded as open to transformation and which treated, consciously or subconsciously, as beyond, or anyway not in need, of critique.

A useful concentration or grouping of this unusually large set of mainstream critical reflections on the nature of modern academic economics is provided by the various contributions to the inaugural (2010) conference (held in Kings College Cambridge) of the Institute for New Economic Thinking (INET), the latter being an organisation set up precisely to transform economics in the light of the failings of the economics discipline to provide much understanding of the crisis.

Very many economists attended the conference, all apparently concerned critically to reconsider the nature of academic economics. It is in such a forum if anywhere that we might hope to find mainstream economists challenging all but the most obviously acceptable aspects of their theories, approaches and activities.

Although George Soros, who sponsors the Institute, shows some awareness that the reliance upon mathematics may at least be something to question (see e.g. Soros, 2009; Lawson, 2010), for most of his close associates the idea that there might be something problematic about the emphasis on forms of mathematical technique does not appear even to cross their minds (all the numerous contributions are posted on the INET website or can be found on Youtube ${ }^{7}$ ).

Consider for example the presentation by Joseph Stiglitz $\left(2010^{8}\right)$, a central contributor in the Institute. Stiglitz quickly focuses on the failure of most models to predict the crisis, he emphasises the need for predictive accuracy, and then he proposes a strategy of experimenting with different model assumptions, most of which are accepted as unrealistic, in order to come up with a best model in terms of forecast accuracy. Or rather Stiglitz makes reference to a "standard model" and declares that the critical question for "research strategy" is to decide which of the model's "many unrealistic assumptions" we "want to drop". Indeed, emphasising the need for pluralism Stiglitz suggests that we "investigate a number of different models where different assumptions are dropped". Stiglitz stresses that, in his view, dynamic models and stochastic models and general equilibrium models remain important for economics, even if it is necessary to revise some of their specifications. His overall preference is seemingly for analytic models or more complex stochastic models that can at least in principle accommodate human interactions (though other preferences for model specifications are listed).

Of relevance here is that, in all this, Stiglitz is seemingly open to entertaining an array of different modelling assumptions (albeit mostly unrealistic ones ${ }^{9}$ ), and so is also open to a degree about policy stances, etc., that might be adopted. The one issue that is not even hinted at, however, is that we might also question the very emphasis on mathematical modelling itself. Indeed the discussion throughout his presentation is only and continually about how economists should go about finding 'better' mathematical models. And this uncritical stance typifies the presentations made throughout the conference, as recorded on INET's website. ${ }^{10}$

Of course, mainstream economists like Stiglitz rarely, and perhaps have little opportunity to, explore in a sustained, serious or systematic way the issues of philosophy/methodology on which they sometimes pronounce. But the same reaction to the crisis is found even by methodologists of the mainstream that

\footnotetext{
${ }^{7}$ See for example http://ineteconomics.org/initiatives/conferences/kings-college or http://www.youtube.com /watch?v=SdZgD1DCNq4

${ }^{8}$ See http://ineteconomics.org/video/conference-kings/agenda-reforming-economic-theory-joseph-stiglitz

${ }^{9}$ Of course, the willingness to entertain unrealistic assumptions makes the whole project rather pointless (see Lawson, 2009a). If I am allowed to make unrealistic assumptions then after the event I can predict anything you want [if the outcome to be so 'forecasted' is $X$, then I can simply (or complexly) assume 1) $Y$ implies $X$, and 2) $Y$ ]. Before the event then, in an open world, successful prediction, if it occurs (involving timing, - like earthquakes we all know crises can and will occur, and usually why) is mostly a matter of luck.

${ }_{10}$ Coincidentally, as I was writing these lines I received via email a paper from INET written by Harald Uhlig (2011), based on his 2010 INET presentation, and entitled 'Economics and Reality' (the same title as my 1997 book). It is a philosophical paper so I thought this might be an exception in at least exploring the relevance and grounding of mainstream mathematical modelling. The author does, in a footnote on page 1, reference my book, and suggest that his piece may, in its philosophical orientation, be "more reminiscent of Lawson (1997)". But the author quickly adds, notably without any argument or explanation, "though I sharply disagree with his [Lawson's] rejection of formal, mathematical models to address the social reality of economics [...]"
} 
might be expected to look deeper and further. Thus in an influential paper entitled "The Financial Crisis and the Systemic Failure of Academic Economics", David Colander, Hans Föllmer, Armin Hass, Michael Goldberg, Katerina Juselius, Alan Kirman, Thomus Lux, and Brigitte Sloth (2008), provide an assessment that again questions anything and everything except the emphasis on formalistic mathematical modelling (see Lawson 2009b; 2009c).

\section{Heterodoxy and mathematical modelling}

In fact so apparently compelling is the belief system in question (that mathematical modelling is the proper way to do economics) that many heterodox economists too seemingly fall under its sway. Although heterodox modellers do not follow the mainstream in dogmatically insisting that we all everywhere adopt a mathematical orientation, it remains the case that many heterodox economists fail to recognise that the conceptions they find to be inadequate in mainstream theory owe something to the mainstream modelling emphasis; and these heterodox economists continue excessively (and often exclusively) to explore alternative mathematical models and forms of mathematical reasoning in the face of explanatory failures and unrealistic formulations.

The heterodox Real-World Economics Review has even seen fit to create a Revere Award for Economics given in large part for success in predicting the Global Financial Collapse, a move that may well further encourage the uncritical reliance on formalistic models and the predictive criterion of success $^{11}$. And whilst the same journal and its associated blog do carry articles and comments that critically focus on the use of mathematics in economics, the dominant emphasis seems to be the exploration of novel, or currently non-standard, forms of mathematical technique ${ }^{12}$.

Of course, I do not wish to (and indeed do not - see e.g. Fullbrook, 2009, especially chapter 12) discourage all experimentation with mathematical models and methods in all contexts, and certainly cannot insist that the use of methods of mathematical- modelling must always be devoid of insight, even if the arguments I have laid out lead me to believe that the current emphasis is largely wasteful of resources (again see Lawson, 1997; 2003). My point rather is that the reliance on mathematical modelling and on criteria like predictive accuracy, goes almost unquestioned throughout much of the economics academy, certainly within the mainstream and sometimes even beyond. And this is so despite the unrealistic concoctions that so far have almost always resulted from this endeavour along with the severe limitation of 11 Of course, I accept (indeed I continually argue) that (using the criteria of explanatory power) we can come to understand the
workings of causal processes and mechanisms (see Lawson, 2009a; or 2003 chapter 4). And where we understand such
mechanisms we can conditionally predict (contingent) tendencies, meaning the impacts of causal forces acting in certain ways or
directions whatever the actual outcomes. Thus I predict that should planet earth survive without catastrophe into tomorrow then over
large parts of the planet there will be gravitational tendencies in play working to 'pull' leaves to the ground, tendencies that will be
operative even as leaves fly over roof tops and chimneys. But, excepting a lucky accident, only in a closure can we predict any
actual outcome (in the case of the path of a specific leaf we must absent aerodynamic and thermodynamic tendencies, the wind,
and so forth).

I acknowledge, too, that because some tendencies are so powerful (relative to countervailing forces) we can even predict certain sorts of outcomes that will eventually occur. Thus given our understanding of the mechanisms behind earthquakes we can reasonably expect that the latter will continue to occur now and again on planet earth. And it is not difficult to understand that capitalism, being an inherently contradictory system, will repeatedly manifest crises. The specific forms and timing though are something else (in such cases the inability to predict outcomes matters little anyway, unless our one goal is to get rich through forms of gambling. Rather what we need to know is how best to locate and construct buildings that can withstand earthquakes; and how to best support social systems that are free of the sorts of contradictions that generate instabilities and crises; and so on. But these matters are not my focus here).

Of course, as with all forms of gambling there is often some forecaster that picks a winner. As I write these lines (end of 2011) there are groups of economists predicting that the euro will collapse, though there is a range of predicted timings of this event; and there are others who expect the euro to survive. There are also anticipations of intermediate paths and outcomes. Each group or commentator is knowledgeably analysing the nature of operative causal mechanisms. But the actual outcomes depend on so many contingent developments including factors yet to be determined. Of course, whatever happens, someone forecasting today will be found after the event to have been closest in their forecasting. But unless they possess the power to effect the result, such 'success' will inevitably be far more luck than judgement.

${ }^{12}$ Though it seems to be something of an easy retort it is surely not wholly without significance, or totally unfair of me, to note that whilst the current paper was posted on the Economic Thought website the majority of comments it received advance the idea that the solutions to the problems I raise lie in continuing the search for more appropriate techniques of mathematical modelling. 
explanatory insight generated by (as opposed to being tagged on to) such activities. And it is so despite the ongoing crises leading economists of all persuasions to critically reflect upon the now-all-too-apparent failings of the academic discipline. All such features I suggest are strongly supportive of the contention that the belief/conviction that 'the only proper economics is a mathematical economics' is a prevailing form of ideology.

\section{Explaining the ideology of mathematical technique in modern economics}

If $\mathrm{I}$ am right about all this then the ideology $\mathrm{I}$ am identifying itself requires an explanation. This is easy enough to provide. But notice first that a feature (I believe it to be a strength) of the explanation of the state of modern economics that I am advancing is that I do not need to invoke a conspiratorial view of ideology (ideology $y_{2}$ ); and specifically I do not at all view the mainstream as a body of dishonest individuals setting out to pull the wool over the eyes of anyone.

Nor of course do Guerrien and others who also emphasise the first interpretation of ideology (ideology ${ }_{1}$ ), but who suppose that mainstream economist are 'blind' to the unrealisticness of their presumption that the political economic system is an efficiently functioning one. But unlike these contributors I also do not need to suppose that mainstream economists or anyone else continue to be blind to the increasingly all-too-apparent crisis-ridden state of capitalist economies.

Still I need to give some reason why mainstream economists may indeed be blind to the possibility that their methods of mathematical modelling are inappropriate to social analysis.

A large part of the explanation, I suggest, is simply that mathematics has been so successful in the history of human endeavour, and especially within (non-social) natural science, that its centrality to all science and serious and systematic investigation is, throughout wide sections of society, taken as an article of faith. Certainly a perception that, especially where measurable quantities are involved, all serious research requires a mathematical form has been widely in evidence since the Enlightenment. And economics is, more than any other social discipline, commonly interpreted as being concerned with measurable quantities (quantity of money, prices, output ${ }^{13}$ ). As such it is not surprising to find many economists both supposing that forms of mathematics are essential to economic science, and optimistic that economics can equally achieve significant mathematical successes eventually.

Thus, whilst Guerrien posits a blindness of mainstream 'intelligent' contributors even when the content of their models is regarded by him as so obviously 'stupid', I only posit a blindness in a situation where it may be understandably difficult for many to see clearly. With the neglect of ontological reasoning, recognition that the current emphasis on formal mathematical modelling in economics is misguided is not so obvious. This is especially the case in the light of the just noted and often emphasised post Enlightenment historical record of mathematical success throughout the various disciplines.

In fact, an acceptance of the idea that mathematics is essential to grounded knowledge has been a factor in sections of popular culture for rather longer even than the post-Enlightenment period. In the interests of brevity let me recall how Morris Kline sums up the introduction to his majestic History of Mathematics in Western Culture:

"In this book we shall survey mathematics primarily to show how its ideas have helped to mould twentieth-century life and thought. The ideas will be in historical order so that our material will range from the beginnings in Babylonia and Egypt to the modern theory of relativity. Some people may question the pertinence of material belonging to earlier historical periods. Modern culture, however, is the accumulation and synthesis of

\footnotetext{
${ }^{13}$ As early as 1871 we find Jevons writing "My theory of Economics, however, is purely mathematical in character [...] To me it seems that our science must be mathematical simply because it deals with quantities" (p. 3)
} 
contributions made by many preceding civilisations. The Greeks, who first appreciated the power of mathematical reasoning, graciously allowing the gods to use it in designing the universe, and then urging man to uncover the pattern of this design, not only gave mathematics a major place in their civilisation but initiated patterns of thought that are basic in our own. As succeeding civilisations passed on their gifts to modern times, they handed on new and increasingly more significant roles for mathematics. Many of these functions and influences of mathematics are now deeply imbedded in our culture" (Kline, 1964).

The influence of mathematics is now so deeply ingrained within our culture, indeed, that many people (especially non-professional scientists) appear to suppose that anything stated in mathematics must be correct, whilst for things to be correct, reliable, insightful or scientific (or at least conferring of scientific status), they must be stated in mathematics ${ }^{14}$. For so many people it seems to be simply an unquestioned and seemingly unquestionable matter of faith that if a field of study is to be scientific or accorded status as a knowledge-producing activity, or otherwise regarded as serious, it must take a mathematical form.

Of course, the Enlightenment did give an important boost to this long-in-evidence perception. And in fact ever since Newton succeeded in uniting heaven and earth in equations, and Kant announced that the study of social phenomena requires its own Newton, the programme of mathematising economics has been underway (see Lawson, 2003, chapter 10).

Interestingly, John Henry (1997) recently observes that following the publication of Newton's Principia, readers "took for granted the validity of mathematics for understanding the working of the world". And he stresses that "although his book met with some fierce criticism, not a murmur was raised against it in [...] regard [to its emphasis on mathematical reasoning]" (p.21)

Actually, from the point of view of understanding the acceptance of the emphasis on mathematisation as ideology, even more interesting is a critical response to Henry provided by Yves Gingras (2001) in his wide-ranging commentary on the history of mathematics. Addressing Henry's assessment that 'murmurs' of dissent against the mathematical formalism were absent from Principia, Gringras writes:

"As we will see, this was far from being the case but to recover these murmurs, one must look at actors who are now unknown precisely because they rejected the mathematization of physics and were thus excluded from the field (and its history) as it evolved in the eighteenth and nineteenth centuries" (Gingras, p. 385)

The point, then, is that a belief that mathematics is central to all science and serious study is a widespread cultural norm of long standing, one that emerged in the face of, and has been continually reinforced through, successes with mathematics throughout the disciplines. If the successes of mathematics has grounded a society-wide cultural belief in the general relevance of, and indeed need for, mathematics for scientific and all serious study, it is not surprising that economists enamoured of the idea of pursuing a serious and scientific economics have too fallen under its sway.

So my contention, in sum, is that the modelling emphasis of modern mainstream economics is explained by a largely unquestioning society-wide conviction (a form of ideology ${ }_{1}$ ) that mathematics is fundamental to all science, a conviction or ideology that itself is in large part explained by the successes of mathematics in so many other domains.

\footnotetext{
${ }^{14}$ Of course this view means turning a blind eye to (or forgetting) the clear scientific successes of the largely non-mathematical disciplines of chemistry and biology in the nineteenth century and indeed much of modern chemistry and bio-medical research (on all this and much that relates to the current paper see Donald Gillies, 2004).
} 


\section{The modern mainstream and the economic system}

I have argued that the malaise of modern economics is not primarily due to ideology at the level of substantive political economy. I have also argued that ideology is present in the economics academy nonetheless, albeit at the level of methodology. Finally, I want to stress that in maintaining these views I do not at all suppose there is no relation between the mainstream stance (that is the insistence that mathematical techniques be everywhere employed) and the underlying economic system. Specifically, and despite the foregoing discussion, I do not at all deny that the mainstream practices can serve the purposes of sustaining the workings of the economic system. But let me be clear on how I think the two do relate.

First, I do not doubt that political-economic and cultural ideological factors in the sense of prevailing background beliefs (ideology ${ }_{1}$ ) are in play in all societies or communities, and are manifest in the contributions and practices of us all. We are all situated and products of our time, place and culture etc. I do not doubt that such background ideology of this sort bears on the sorts of questions we ask, the orientations we adopt, the assumptions, including absences, we take for granted, the states of affairs we regard as 'normal', and so on. However, I do not think the very real ideological beliefs that prevail regarding the benefits or 'normality' of the existing political-economy system are primarily or even significantly responsible for the perpetual failings and acknowledged fictions of contemporary academic economics. This is just to repeat the foregoing. Most economists as academic researchers do not even seem interested in the economy as such anyway. Far more important is their prowess in manipulating mathematical models and such like. The dominant ideology in the economics academy, I am maintaining, is precisely the extraordinarily widespread and long-lasting belief that mathematical modelling is somehow neutral at the level of content or form, but an essential method for science, underpinning any proper or serious economics.

Second, and following on from the above, the scandal, of modern economics is not that it gets so many things wrong, but that it is so largely irrelevant. However in being irrelevant, and yet using significant resources that could have been used for research into the way the economy really works, then, at a time that the economy is in crisis and proving largely dysfunctional, the mainstream modelling orientation cannot but serve to deflect criticism from the nature of the status quo at the level of the economy and thereby work to sustain it (and would do so whatever that status quo happened to be). As Leamer, (already noted above) observes, no one takes anyone else's data analysis seriously. In truth, few people take any mainstream analyses seriously, except in economics faculties' promotion exercises.

Third, if however anyone were to pay much attention to mainstream analysis, it would serve to sustain, if not reinforce, the status quo in an additional way. The point here is that the emphasis on event regularities (necessitated by a reliance on forms of mathematical modelling), and so attachment to an implicit ontology of closure and atomism, entails that any references to social relationality, and so to (relational) issues of power, discrimination, domination, oppression, and conflict generally, are effectively masked over or hidden, or at best trivialised. For the framework is ill-equipped even to allow such categories to be seriously considered. Thus the very emphasis on mathematical modelling renders analyses of real conflict, power relations and social transformation effectively if inadvertently precluded.

\section{The persistence of mathematical reasoning}

I am accepting, then, that although the generalised malaise of modern economics does not reflect any ideological attachment to specific economic theories, the persistent irrelevance of academic mainstream economics, resulting from the emphasis on formal modelling, is nonetheless inhibiting of analysis capable of constituting meaningful constructive criticism of existing political-economic states of affairs. Moreover this consequence, which, I stress, I take to be largely unintended, does, I believe, contribute to explaining how the mathematical project persists in maintaining institutional power in the face of, and despite, its repeated 
failures and fictitious constructions. For government sponsored funding bodies and the like are actually less likely to withdraw funds from a project that provides no serious criticism of the government's actions.

Parenthetically, I believe this inability of the mathematical modelling project to challenge anything seriously or convincingly is a major factor in understanding how the project has survived as long as it has in the economics academy, and even how it originally came to dominate. Elsewhere, I address at length the reasons for the rise and persistence of a mainstream tradition that so clearly lacks a history of explanatory successes $^{15}$ (see especially chapter 10 of Lawson, 2003).

I stress once more, however, that in all this I am not suggesting that those who contribute to the mathematising project in economics do so, in the main, opportunistically. Rather I merely point out that whatever its advocates' intentions, the mainstream project (with its emphasis on mathematical deductivist modelling, and lack of criticality) may appear, and at times has indeed proven to be (see Lawson, 2003, chapter 10), conducive to those, especially outside the academy, seeking, for whatever reason, to deflective or minimise intellectual challenges to the underlying economic system. As such, this mathematical project, itself underpinned by methodological ideology, and not formulated by those pushing, or duped by, a political-economy ideology, might nevertheless be said to contribute ultimately to sustaining the status quo.

\section{Conclusion}

My contention, in short, is that contemporary academic mainstream economics is indeed often underpinned by ideology. But this ideology is first of all methodological in nature, being in effect the widespread cultural view that mathematics is essential to science. Incidentally I argue elsewhere not only that this ideology covers a false view in that successful natural science does not actually rest on the application of mathematics, but also that a nonmathematical economics can actually yet be a science in the sense of the successful natural sciences (see Lawson, 1997; 2003 and especially 2012).

I have suggested too that a possible, and indeed likely, reason the mathematical emphasis of the mainstream project does not come under more critical scrutiny from outside the academy is that the project's continuing irrelevance actually renders it harmless to political defenders of any prevailing status quo who might otherwise be drawn to more critical considerations in connection with funding and the like.

Although I have attempted here to explain the continuing misplaced emphasis on techniques of mathematical modelling in the economics academy I might add that I do not suggest that there are not yet factors at play additional to those I have identified. Amongst other things, the longish recent history of

\footnotetext{
${ }^{15}$ In the context of the last 200 years of economic thinking, the fortunes of the project of seeking to mathematise economics have notably waxed and waned in line with changes in the relevant background academic environment, not least in responses to developments in forms of mathematics itself (again see Lawson, 2003, chapter 10).

But certainly no less important were changes in the political environment both inside and outside the academy. One significant feature of the latter was the influence of the political environment in the US following the Second World War. The situation in the US in this period is especially important to understanding the subsequent path of modern economics, just because the resources of the US in the early post-war period allowed it to dominate much of the post world war II international academic scene (in economics as in many other disciplines).

A very significant feature of the early Post World War II political environment was the emergence in the US of McCarthyite witch-hunts in the face of the Cold War. In this climate, the nature of the output of economics faculties became a particularly sensitive matter. And in such a context, the project of seeking to mathematise economics proved to be especially appealing. For although it carried scientific pretensions it was significantly devoid of any necessary empirical content (especially when carried out in the spirit of the Bourbaki approach - see Lawson, 2003).

The group most feared or resented by the McCarthyites were the intellectuals (see e.g., Erik Reinert, 2000). The formalising project with an emphasis on mathematical structure to the exclusion of almost any critical or reflexive content was clearly extremely attractive to those caught up in the situation. This was especially the case not just for insecure or fearful university administrators but also for the funding agencies of US social scientific research (who were especially important in this period - see for example, Bob Coats, 1992; Crawford Goodwin, 1998; Yuval Yonay, 1998).

In fact, historians of the US have long argued that McCarthyism and the Cold War were decisive in the growth of antiintellectualism in the US in the twentieth Century. (see e.g., Richard Hofstadter's [1963] Anti-Intellectualism in American Life; or Alan Bloom's [1987] The Closing of the American Mind). My point here is simply that this environment impacted on the economics faculties as elsewhere, and was doubtless conducive to the spread of economics as merely a form of technicist manipulation, with little attachment paid to, or with little consistency in, economic content (see Reinert, 2000 for a similar conclusion ${ }^{15}$ ). On all this see Lawson, 2003, chapter 10
} 
mainstream perseverance with the deductivist modelling techniques in the face of repeated failure has suggested to some that there may also be something pathological to what is going on, and that a psychological explanation is likely also of some relevance. Also, the pattern of behaviour in question seems to be gendered, with the mathematical modelling and prediction activities being relentlessly pursued largely by gendered males. This too seems to warrant explanation (again see Lawson, 2003, chapter 10). These are issues that are currently receiving attention elsewhere and in illuminating ways ${ }^{16}$. But that, as they say, is another story.

For now it does seem safe to conclude that the primary explanation of the numerous, long lived and continuing failings of modern academic economics is the (misplaced) emphasis on mathematical modelling. It is an emphasis underpinned by the cultural belief that a reliance on mathematical technique in science is somehow so normal or neutral or natural that any questioning of this emphasis can be ignored or swiftly dismissed as obviously far too radical if not nonsensical.

\section{Acknowledgements}

The writing of this paper benefitted from the financial support of the Independent Social Research Foundation. For helpful comments on an initial draft posted on the Economic Thought website I am grateful to Jānis Bērzinš, Frederico Botafogo, Thomas Bowen, Dick Burkhart, Lynne Chester, Donald Gillies, Egmont Kakarot-Handtke, Roy Langston, Bruce Littleboy, Jamie Morgan and Patrick Spread.

\section{References}

Bigo, Vinca (2008), "Explaining Modern Economics (as a microcosm of society)", Cambridge Journal of Economics, 32(4):527-554.

Bloom, Allan (1987) The Closing of the American Mind, New York: Simon And Schuster

Coats, A.W. Bob (1992) On the History of Economic thought: British and American Economic Essays, Volume I, London and New York: Routledge.

Colander, David, R. P. Holt and J.B. Rosser Jr. (2004). 'The changing face of mainstream economics', Review of Political Economy, vol. 16, no. 4, 485-500

Colander, David, Hans Föllmer, Armin Hass, Michael Goldberg, Katerina Juselius, Alan Kirman, Thomus Lux, and Brigitte Sloth (2008), "The Financial Crisis and the Systemic Failure of Academic Economics", unpublished mimeo, available at:

http://www.debtdeflation.com/blogs/wp-content/uploads/papers/Dahlem_Report_EconCrisis021809.pdf

Davis, John B. (2005). 'Heterodox economics, the fragmentation of the mainstream and embedded individual analysis', in Garnett, R. and Harvey, J. (eds.), The Future of Heterodox Economics, Ann Arbor, MI, University of Michigan Press.

Dixon, Huw (1990), 'Equilibrium and Explanation', in John Creedy (ed.) Foundations Of Economic Thought, Oxford: Basil Blackwell.

Eagleton, Terry (1991), Ideology: An Introduction, London: Verso.

\footnotetext{
${ }^{16}$ See for example Vinca Bigo, 2008.
} 
Fullbrook, Edward (2009) Ontology and Economics: Tony Lawson and His Critics, London and New York: Routledge.

Gillies, Donald (2004) 'Can Mathematics be used Successfully in Economics?' in Edward Fullbrook (ed.), A Guide to What's Wrong With Economics, London: Anthem Press, pp. 187-97

Gingras, Yves (2001) 'What did Mathematics do to Physics?' History of Science, xxxix, pp 383-416.

Goodwin, Crawford. D. (1998) 'The Patrons of Economics in a Time of Transformation', in Morgan Mary S. and Rutherford, Malcolm (eds.) From Interwar Pluralism to Postwar Neoclassicism, Annual Supplement to Volume 30, History of Political Economy, Duke and London: Duke University Press.

Guerrien, Bernard (2004) "Irrelevance and Ideology ", Post-autistic Economics Review, issue no. 29, 6 December 2004, article 3,

Hahn, Frank H. (1994) 'An Intellectual Retrospect', Banca Nazionale del Lavoro Quarterly Review: 245-258.

Hahn, Frank H. (1970) 'Some adjustment problems', Econometrica, vol. 38, January; reprinted as pp. 117 in Equilibrium and Macroeconomics, Oxford, Basil Blackwell.

Hahn, Frank H. (1982) Money and Inflation, Oxford: Basil Blackwell

Hahn, Frank H. (1992a) 'Reflections', Royal Economics Society Newsletter 77.

Hahn, Frank H. (1992b) 'Answer to Backhouse: Yes', Royal Economic Society Newsletter 78: 5.

Henry, John (1997) The Scientific Revolution and the origins of modern science, New York.

Hofstadter, Richard (1963) Anti-Intellectualism in American Life New York: A.A. Knopf.

Jevons, W. Stanley (1965 [1871]) The Theory of political Economy, New York, Reprints of Economic Classics, Augustus M. Kelley.

Kanth, Rajani (1999) 'Against Eurocentred Epistemologies: a critique of science, realism and economics', in Steven Fleetwood (ed.), Critical Realism in Economics: development and debate, London and New York: Routledge

Kirman, Alan (1989) 'The Intrinsic Limits of Modern Economic Theory: The Emperor has no clothes', Economic Journal 99(395), pp. 126-139.

Kline, Morris (1964) Mathematics in Western Culture, Oxford: Oxford University Press.

Lawson, Tony (1997) Economics and Reality, London and New York: Routledge.

Lawson, Tony (2003) Reorienting Economics, London and New York: Routledge.

Lawson, Tony (2005) 'The (Confused) State of Equilibrium Analysis in Modern Economics: an (Ontological) Explanation', Journal for Post Keynesian Economics, 27: 3 (Spring) pp. 423-44. 
Lawson, Tony (2006) 'Tensions in Modern Economics. The case of Equilibrium Analysis', in Valeria Mosini (ed.), Equilibrium in Economics: Scope and Limits, London and New York: Routledge.

Lawson Tony (2009a) 'Applied Economics, Contrast Explanation and Asymmetric Information', Cambridge Journal of Economics, 33:3, May, pp. 405-20.

Lawson, Tony (2009b) 'The Current Economic Crisis: its Nature and the Course of Academic economics', Cambridge Journal of Economics, 33:4, July, pp. 759-788.

Lawson, Tony (2009c) 'Contemporary Economics and the Crisis', Real-World Economics Review, 50, pp $122-31$.

Lawson, Tony (2010) 'Soros's Theory of Reflexivity: a critical comment', mimeo: Cambridge

Lawson, Tony (2012) 'Ontology and the Study of Social Reality: Emergence, Organisation, Community, Power, Social Relations, Corporations, Artefacts and Money, Cambridge Journal of Economics, 36:2, March, pp 345-386

Leamer, Edward E. (1978) 'Specification Searches: Ad hoc inferences with non-experimental data', New York: John Wiley and Sons.

Leamer, Edward E. (1983) 'Lets take the Con out of Econometrics', American Economic Review: 34-43.

Muth, John F. (1961) 'Rational Expectations and the Theory of Price movements', Econometrica, Vol. 29, No. 3 (July, 1961), pp. 315-335.

O'Boyle, Brian and Terrence McDonough (2011) "Critical realism, Marxism and the Critique of Neoclassical Economics", Capital and Class, February, 35: 3-22: also found at http://goliath.ecnext.com/coms2/gi 0199-14565044/Critical-realism-Marxism-and-the.html

Reinert, Erik. S. (2000) 'The Austrians and 'The Other Canon", in Backhaus, J (ed.) The History of Evolutionary Economics, Aldershot: Edward Elgar.

Rubinstein, Ariel (1995) 'John Nash: the master of economic modelling', Scandinavian Journal of Economics 97(1): 9-13.

Söderbaum, Peter (2009) "A financial crisis on top of the ecological crisis: Ending the monopoly of neoclassical economics", Real-World Economics Review, issue no. 49, 12 March, pp. 8-19, http://www.paecon.net/PAEReview/issue49/Soderbaum49.pdf

Soros, George (2009) The Crash of 2009 and What it Means: The New Paradigm for Financial Markets, New York: Public Affairs.

Stiglitz, Joseph (2010) An Agenda for Reforming Economic Theory, presentation at 2010 INET Conference at Kings College Cambridge. See

http://ineteconomics.org/video/conference-kings/agenda-reforming-economic-theory-joseph-stiglitz 
Uhlig, Harald (2011) 'Economics and Reality', mimeo: University of Chicago, forthcoming: Journal Of Macro Economics.

Yonay, Yuval P. (1998) The Struggle Over the Soul Of Economics: Institutionalist and Neoclassical Economists in America Between the Wars, Princeton: Princeton University Press. 